\title{
INTEROPERABLE MODEL FOR BIORESOURCE DISTRIBUTED DATABASES
}

\author{
Sameer Saran ${ }^{1, *}$, Priyanka Singh $^{1}, \mathrm{KN}$ Ganeshaiah ${ }^{2}$, Hitendra Padalia $^{1}$, Kapil Oberoi $^{1}$ \\ ${ }^{1}$ Indian Institute of Remote Sensing, Dehradun, India - sameer@iirs.gov.in, priyanka.iirs@gmail.com, \\ (hitendra, kapil)@iirs.gov.in \\ ${ }^{2}$ University of Agricultural Sciences, GKVK, Bangalore, India - knganeshaiah@gmail.com
}

\section{Commission V, SS: Utilization of Bio-Resource National Databases}

KEY WORDS: Bioresource, Interoperability, Data Standards, Metadata Standards, OGC

\begin{abstract}
:
Recently, numerous frameworks and tools are being developed for enhancing access to data and services with a standardized view to communicate the advances in open information sharing. Another emerging field of data exploration is encountered in the coordination, examination and perception of bioresource data and are prompting corresponding new innovations. The bioresource information team aims to develop standards for nationwide data exchange by the establishment of a catalog service to locate and access biological data and information from across the country and information tool for decision makers. With the growth of open data sharing initiatives, the sharing of data among different and myriad sources has increased significantly, but major challenge lies in addressing the issues of interoperability during exchange and use since the data sources are heterogeneous and the data being organization specific is prepared with different (organization) specific data standards and platforms. This paper presents the model based on the study of different metadata standards and to develop a recommended standard for biodiversity information to support interoperability among heterogeneous databases under the umbrella of Indian Bioresource Information Network (IBIN) portal. The paper presents the mapping of different data standards into the IBIN standard for sharing species data in the form of distributed and interoperable web services to set the stage for interoperability
\end{abstract}

\section{Introduction}

With the growth of open data sharing initiatives, the sharing of data among different systems has increased significantly, but major challenge lies during exchange and access since the data sources are heterogeneous and the data being vendor specific is dependent on the ways in which the data has been collected, labelled and stored in a specific standard and platform. However, data may be shared between two parties of same domain about with a simple longhand note, there is unquestionably a need for more documentation in the case of multidisciplinary teams working over multiple sites and scales.

The task of making data available across the domain and after some time is in general an unfunded mandate which requires a special kind of alertness to prepare a specific set of protocols for data in such a ways beyond what the user needs for its immediate utilization. The resultant specific set of protocols - data standards - are being developed to allow and ease the interconnection of disparate systems and thereupon the free flow of data. Data standards are characterized as a consensual specifications for the representation of data from heterogeneous sources or platforms. Data standards may be called as a benchmark required for the sharing, portability, and reusability of data
(Chalmers 2006; Dudeck 1998; Kohn et al. 2000). Therefore, In order to understand the capacity of distributed and collective scientific work, there is a need to understand the standards, particularly, the forms and functions of 'metadata' - data about data - standards (Michener et al. 1997).

\section{Metadata Standards}

In various domains such as multimedia (Smith and Schirling 2006), educational resources (McClelland 2003), web (Bodoff et al. 2005), clinical research (Richesson and Krischer 2007), statistical methods (Bargmeyer and Gillman 2000), geospatial applications (Federal Geographic Data Committee 1998) and biodiversity (Costello and Wieczorek 2013) where the data is exponentially increasing on the order of petabytes annually, metadata was discovered in this digital era to help computer systems and human being in order to collect, organize, access and interpret data (van senbruggen et al. 2004; Kosch et al. 2005). Generally, metadata is loosely defined as "data about data".

According to the author of (Barkman et al. 2002), metadata is defined as

* Corresponding author 
"information about an object, be it physical or digital".

Thus, domain-specific metadata standards are the focal point in the rapid development of digital libraries and repositories (Chan and Zeng 2006; Fox et al. 1995). Basically, the users of such a digital world ""should be able to discover through one search what digital objects are freely available from a variety of collections, rather than having to search each collection individually" (Tennant 2001). Moreover, the aim of metadata is "to facilitate search, evaluation, acquisition, and use" of resources (Barkman et al. 2002). Various metadata standards have been developed, and many more are in the progress to meet the specific domain of interest, for example, DublinCore (DCMI 2007), USMARC (Carini and Shepherd 2004), Federal Geographic Data Committee (FGDC) (Federal Geographic Data Committee 1998), Survey Design and Statistical, Methodology (SDSM) (LaPlant et al. 1996), Ecological Metadata Language (EML) (Fegraus et al. 2005), Darwin core (DwC) (Wieczorek et al. 2012), and Metadata Object and Description Schema (MODS) and Metadata Encoding and Transmission Standard (METS) (Guenther and McCallum 2003).

As mentioned by the author of (Chan and Zeng 2006), metadata element set has two basic components:

- Semantics - This deal with the definitions of the meanings of the elements and their refinements.

- Content - This deal with the declarations or instructions of what and how values should be assigned to the elements.

The metadata element set and an appropriate vocabulary as values for the elements is a first step in describing any resource. Each element is repeatable and optional, and the entire set is extensible (Harper 2010)

Normally, metadata standards are categorized with respect to its application purpose, as business standard and technical standards (Vetterli et al. 2000). The technical metadata standards include schema definitions and configuration specifications, physical storage information, access rights, executable specifications like data transformation and plausibility rules, and runtime information like log files and performance results (Vetterli et al. 2000). However, technical standards are much more relevant because they played a key role in developing interoperable tools and services (Paepcke et al. 1998) and are required to support interoperability to distribute, create and manage data across platform.

\section{Interoperability}

The definition of Interoperability as given by Open Geospatial Consortium (OGC) is "the capability of a system or its components to repress the access obstacles to distributed resources forced by heterogeneous data and complex processing environments by means of a uniform interface" (Schell et al. 2000). In simple terms, Interoperability is considered as the capability to exchange and utilise information, typically characterized in the connection of a vast system made up of heterogeneous frameworks. OGC is now working not to develop another standard for geodata, but for the standard way for utilizing the existing standards in various applications in heterogeneous data environments and distributed processing applications (Schell et al. 2000).

\section{Layers of Interoperability}

There are various layers of interoperability identified in the literature, namely Protocol, Data Binding, Metadata Schemes, and Semantics, as listed in Table 1 (Duh et al. 2001). The topmost layer of interoperability is network protocol interoperability including TCP/IP and HTTP standards. These standards empower web browser and server to exchange messages in the form of request and response, despite of the different software components being developed and executed on different operating systems, hardware, etc. Second layer is data binding where data gets bound in particular format for representation, for example, representation of a document in HTML, XML and RDF is used for metadata binding. The third level that described in this paper is metadata scheme which provides the specifications of the data elements of which the metadata instance is composed of. Metadata instances based on a common metadata schema have a high degree of 'semantic interoperability' (Forte et al. 1999). The fourth and last layer is semantic that includes ontologies, classifications, vocabularies and taxonomies to define the domain specific concepts and their interrelationships.

Table 1. Layers of interoperability (Source: Duval 2001)

\begin{tabular}{ll}
\hline Protocol & TCP/IP, HTTP \\
\hline Data binding & $\begin{array}{l}\text { HTML, XML, } \\
\text { RDF }\end{array}$ \\
\hline Metadata scheme & $\begin{array}{l}\text { LOM, Dublin } \\
\text { Core }\end{array}$ \\
\hline Semantic & $\begin{array}{l}\text { Ontologies, } \\
\text { classifications, } \\
\text { vocabularies, } \\
\text { taxonomies }\end{array}$ \\
\hline
\end{tabular}

Interoperability prevent end users from being averted into the proprietary systems by "enabling information that originates in one context to be used in another in ways that are as highly automated as possible" (Rust and Bide 2000). For example, World Wide Web (WWW) can be seen as a base of interoperable system that allow users to choose client and server (Berners-Lee, T. and M 1999). The challenges of metadata interoperability can be resolved at various levels, as mentioned by author of Haslhofer and Klas 2010:- "on a lower technical level, machines must be 
able to communicate with each other in order to access and exchange metadata. On a higher technical level, one machine must be able to process the metadata information objects received from another. And on a very high, semantic level one must ensure that machines and humans correctly interpret the intended meanings of metadata."

\section{Metadata Standards in Biodiversity}

Bioresource information is fundamental and a key to decision making for a wide extent of scientific, educational, and governmental organizations. The term "biodiversity" comprises the diversities of plants, animals and other living things of a particular region or area (Heidorn 2002). The representation of biodiversity data are done using the principles of taxonomy. Taxonomy implies hierarchical approach to describe the organisms into different groups on the basis of their adapted characteristics and reflecting postulated evolutionary relationships between these groups (Paterson and Kennedy 2004). Henceforth, different taxonomic classifications and unambiguous labelling of these groups leads to a problem of integration and exchange of diverse datasets (Kennedy et al. 2006). This form of heterogeneity in biodiversity domain doesn't occur due to the non-standardized data storage but also because of diverse datasets and evolution of new form of information. The storage and distribution of bioresource information requires the integration of information on a single platform for data analysis and interpretation (Hoffmann et al. 2014). Seamless integrating and exchange of information from distributed sources into a single system is not a simple procedure, and therefore requires the need of open data standards. The standards provide a definite set of rules and protocols to share information, making the integration much more straightforward to share the data. The use of standards will enable/enhance the interoperability among the systems for seamless integration of information. For example, non-governmental organisations such as International Organisation for Standardisation (ISO) uses standards and facilitates all the reciprocal needs of commercial and non-commercial needs of the community. The biodiversity related organisations such as government sector, natural history museums, universities and other private institutions are working on to develop common standardized model as a rule, protocol or guideline for exchanging data among them and supports distributed querying and responses for that queries. The globally reviewed metadata standards in biodiversity domain are researched and discussed in this section.

\section{Review of Global Species Data Standards}

When considering the task of sharing data- the specific data standards address the question of what information can be shared and the protocols address the question of how the information is to be shared and accessed. Following are the metadata standards supported for sharing different types of species data:
i. Darwin Core
ii. Ecological Metadata Language (EML)
iii. Plinian Core
iv. Species Profile Model (SPM)
v. Access to Biological Collections Data (ABCD)

Table 2. Metadata Standards

\begin{tabular}{|c|c|c|c|}
\hline Standards & Organization & Purpose & AccessURL \\
\hline $\begin{array}{l}\text { Darwin Core } \\
\text { (DwC) }\end{array}$ & $\begin{array}{l}\text { Taxonomic Databases } \\
\text { Working Group (TDWG) }\end{array}$ & $\begin{array}{l}\text { The Darwin Core is a metadata specification } \\
\text { for information about the geographic } \\
\text { occurrence of species and the existence of } \\
\text { specimens in collections (Wieczorek et al. } \\
\text { 2012). }\end{array}$ & http://rs.tdwg.org/dwc/ \\
\hline $\begin{array}{l}\text { Ecological } \\
\text { Metadata } \\
\text { Language (EML) }\end{array}$ & $\begin{array}{l}\text { Ecological Society of } \\
\text { America }\end{array}$ & $\begin{array}{l}\text { EML is a metadata specification particularly } \\
\text { developed for the ecology discipline (Fegraus } \\
\text { et al. 2005). }\end{array}$ & $\begin{array}{l}\text { https://knb.ecoinformatics. } \\
\text { org/ }\end{array}$ \\
\hline Plinian Core & $\begin{array}{l}\text { Taxonomic Databases } \\
\text { Working Group (TDWG) }\end{array}$ & $\begin{array}{l}\text { Plinian Core is a standard oriented to share } \\
\text { species level information (Working group for } \\
\text { the development of the Plinian Core standard } \\
\text { 2017). }\end{array}$ & $\begin{array}{l}\text { https://code.google.com/p/ } \\
\text { pliniancore/wiki/About }\end{array}$ \\
\hline $\begin{array}{l}\text { Species Profile } \\
\text { Model (SPM) }\end{array}$ & $\begin{array}{l}\text { Taxonomic Databases } \\
\text { Working Group (TDWG) } \\
\text { and Encyclopedia of Life } \\
\text { (EOL) }\end{array}$ & $\begin{array}{l}\text { SPM is intended to be a specification of data } \\
\text { concepts and structure intended to support the } \\
\text { retrieval and integration of data that } \\
\text { documents species, e.g., facts about biology, } \\
\text { ecology, evolution, behaviour, etc. (TDWG } \\
\text { 2016). }\end{array}$ & $\begin{array}{l}\text { http://maps2.eol.org/info/9 } \\
8 \\
\text { http://wiki.tdwg.org/twiki/ } \\
\text { bin/view/SPM/SpeciesProf } \\
\text { ileModel }\end{array}$ \\
\hline $\begin{array}{l}\text { Access to } \\
\text { Biological }\end{array}$ & Taxonomic & $\begin{array}{l}\text { It is intended to support the exchange of data } \\
\text { about specimens and observations (ABCD }\end{array}$ & http://www.tdwg.org/activi \\
\hline
\end{tabular}




\begin{tabular}{llc}
\hline $\begin{array}{l}\text { Collections Data } \\
\text { (ABCD) }\end{array}$ & Working Group (TDWG) 2016). ties/abcd/ \\
\hline
\end{tabular}

With the growth of open data sharing initiatives, the sharing of data among different systems has increased significantly, but major challenge lies in addressing the issues of Interoperability during exchange and use since the data sources are heterogeneous and the data being vendor specific is prepared with different vendor specific data standards and platforms.

As the number of elements in the above defined metadata standards increases, the errand of facilitating metadata in different standards turns out to be more troublesome and monotonous. In order to minimize the expense of time for the creation and support of metadata and to maximize its convey to the wider audience of users, it should be desirable to develop a unique standard for species data to store and provide automated views of metadata. Using the core elements of the above defined data standards, a standard for bioresource information is defined for the interoperability between providers and Indian Bioresource Information Network (IBIN) portal. This paper presents the model based on the study of different metadata standards and to develop a recommended standard for biodiversity information to support interoperability among heterogeneous databases. The paper presents the mapping of different data standards into the IBIN standard for sharing species data in the form of distributed and interoperable web services to achieve interoperability. The

Table3. Mapping of Different Standards into IBIN Schema paper highlights the long ranged question of finding the finest long-range solution for facilitating data sharing and interoperability through the "Web Services". Web services provide an open, interoperable, and highly efficient framework for implementing systems. Biodiversity data access through new software tools, web services, and architectures will convey new opportunities and dimensions to novel methodologies in ecological analysis, predictive modeling, and combination and representation of biodiversity information (Canhos et al. 2004).

\section{Mapping of data elements}

The mapping of various elements of different global metadata standards to IBIN standard is to be done by mapping the database attributes (fields) of the global metadata standards to the elements of the IBIN database schema. For instance, an attribute TaxonRecordID in the table of IBIN's local database corresponds to the Dataset_ID attribute in the Plinian Core. After accomplishing this step, the element set of the global metadata standards and their semantics will be mapped into the semantics of IBIN element set [11] which can be deployed in different application profiles in the form of web services and XML schema [12]. After mapping the elements, the data coming from heterogeneous sources will be published. The mapping is enlisted in Table 2 .

\begin{tabular}{|c|c|c|c|c|}
\hline Category & Term Name & Standards & IBIN Standard & Use \\
\hline \multirow[t]{4}{*}{ Base Elements } & DataSet_ID & Plinian Core & TaxonRecordID & $\begin{array}{l}\text { Unique identifier of the record } \\
\text { within the IBIN database. }\end{array}$ \\
\hline & GlobalUniqueIdentifier & Darwin Core & GlobalUniqueIdentifier & $\begin{array}{l}\text { Global unique identifier for } \\
\text { the specimen or observation } \\
\text { record. }\end{array}$ \\
\hline & Description & Plinian Core & Abstract & $\begin{array}{l}\text { Summarize the most relevant } \\
\text { or attractive characteristics of } \\
\text { this taxon to the general } \\
\text { public. }\end{array}$ \\
\hline & Basis of record & Darwin Core & RecordBasis & $\begin{array}{l}\text { An abbreviation indicating } \\
\text { whether the record represents } \\
\text { an observation }(\mathrm{O}) \text {, a collected } \\
\text { living organism, (L), a } \\
\text { specimen in } \\
\text { collection/museum (S), a } \\
\text { collected germplasm/seed (G), } \\
\text { a photo }(\mathrm{P}) \text {, or derived from } \\
\text { literature, where original basis } \\
\text { unknown (D). }\end{array}$ \\
\hline $\begin{array}{l}\text { Nomenclature and } \\
\text { Classification }\end{array}$ & Scientific Name & EOL SPM & Scientific Name & $\begin{array}{l}\text { Canonical name enforcing } \\
\text { strict inclusion of only }\end{array}$ \\
\hline
\end{tabular}




\begin{tabular}{|c|c|c|c|c|}
\hline & vernacularName & $\begin{array}{lr}\text { EOL } & \text { SPM, } \\
\text { Darwin } & \text { Core, } \\
\text { EML, } & \text { Plinian } \\
\text { Core } & \end{array}$ & $\begin{array}{l}\text { Common/ } \\
\text { Names }\end{array}$ & $\begin{array}{l}\text { A list of common and } \\
\text { vernacular names, in } \\
\text { alphabetic order, optionally } \\
\text { followed by language and } \\
\text { region where it is used. }\end{array}$ \\
\hline & Synonyms & $\begin{array}{lr}\text { EOL } & \text { SPM, } \\
\text { Darwin } & \text { Core, } \\
\text { EML, } & \text { Plinian } \\
\text { Core } & \end{array}$ & Synonyms & $\begin{array}{l}\text { A list of alternate scientific } \\
\text { names by which the taxon is } \\
\text { known. }\end{array}$ \\
\hline & Hierarchy & $\begin{array}{lr}\text { EOL } & \text { SPM, } \\
\text { Darwin } & \text { Core, } \\
\text { EML, } & \text { Plinian } \\
\text { Core } & \end{array}$ & TaxonomicHeirarchy & $\begin{array}{l}\text { Hierarchical categories of the } \\
\text { taxon }\end{array}$ \\
\hline \multirow[t]{3}{*}{ Description } & $\begin{array}{l}\text { General/Morphology/Life } \\
\text { Form }\end{array}$ & $\begin{array}{l}\text { EML, Plinian } \\
\text { Core, EOL SPM }\end{array}$ & $\begin{array}{l}\text { General/Morphology/Life } \\
\text { Form }\end{array}$ & $\begin{array}{l}\text { Description of the general } \\
\text { appearance of the taxon; e.g } \\
\text { body plan, shape and color of } \\
\text { external features, texture, } \\
\text { orientation and typical } \\
\text { postures. }\end{array}$ \\
\hline & Diagnostic Description & EOL SPM & Diagnostic & $\begin{array}{l}\text { A description of the features } \\
\text { that distinguish this taxon } \\
\text { from close relatives or other } \\
\text { similar species. }\end{array}$ \\
\hline & TaxonomicalDescription & Plinian Core & $\begin{array}{l}\text { SubspeciesVarietiesRaces } \\
\text { Strains }\end{array}$ & $\begin{array}{l}\text { Information on infraranks, } \\
\text { *subspecies, varieties, races } \\
\text { and strains* }\end{array}$ \\
\hline \multirow[t]{6}{*}{ NaturalHistory } & Cyclicity & EOL SPM & Cyclicity & $\begin{array}{l}\text { Those states or conditions } \\
\text { characterised by regular } \\
\text { repetition in time. }\end{array}$ \\
\hline & Reproduction & EOL SPM & Reproduction & $\begin{array}{l}\text { Description of reproductive } \\
\text { physiology and behaviour, } \\
\text { including mating and life } \\
\text { history variables. Includes } \\
\text { cues, strategies, restraints, } \\
\text { rates. }\end{array}$ \\
\hline & Migration & EOL SPM & Migration & $\begin{array}{l}\text { Description of the periodic } \\
\text { movement of organisms from } \\
\text { one locality to another }\end{array}$ \\
\hline & Dispersal & EOL SPM & Dispersal & $\begin{array}{l}\text { Description of the methods, } \\
\text { circumstances, and timing of } \\
\text { dispersal }\end{array}$ \\
\hline & Associations & EOL SPM & Associations & $\begin{array}{l}\text { Descriptions (in narrative } \\
\text { form) of taxa that interact with } \\
\text { the subject taxon. }\end{array}$ \\
\hline & & EOL SPM & Diseases & $\begin{array}{l}\text { Description of diseases that } \\
\text { the organism is subject to. }\end{array}$ \\
\hline \multirow[t]{2}{*}{$\begin{array}{l}\text { MolecularCharacte } \\
\text { risation }\end{array}$} & ChromosoneNumber & IBIN & ChromosoneNumber & \multirow{2}{*}{$\begin{array}{l}\text { Information on the cytology, } \\
\text { genetics and biochemical } \\
\text { details of the taxon }\end{array}$} \\
\hline & Ploidy & IBIN & Ploidy & \\
\hline
\end{tabular}




\begin{tabular}{|c|c|c|c|c|}
\hline & TotalDNAContent & IBIN & TotalDNAContent & \\
\hline & $\begin{array}{l}\text { MolecularChemicalMarke } \\
\text { rs }\end{array}$ & IBIN & $\begin{array}{l}\text { MolecularChemicalMarke } \\
\text { rs }\end{array}$ & \\
\hline \multirow[t]{3}{*}{$\begin{array}{l}\text { HabitatLocationDi } \\
\text { stribution }\end{array}$} & Habitats & EOL SPM & Habitat & $\begin{array}{l}\text { General description of the sites } \\
\text { where the species is found. }\end{array}$ \\
\hline & Location & $\begin{array}{l}\text { Darwin Core, } \\
\text { Plinian Core, } \\
\text { EOL SPM }\end{array}$ & Location & $\begin{array}{l}\text { Coordinates of the location } \\
\text { where the taxon was sighted or } \\
\text { the specimen collected. }\end{array}$ \\
\hline & Distribution & $\begin{array}{l}\text { Darwin Core, } \\
\text { Plinian Core, } \\
\text { EOL SPM }\end{array}$ & Distribution & $\begin{array}{l}\text { Enumeration of geographic } \\
\text { entities where the taxon lives. }\end{array}$ \\
\hline \multirow[t]{3}{*}{$\begin{array}{l}\text { DemographyConse } \\
\text { rvation }\end{array}$} & Population Biology & $\begin{array}{l}\text { EOL SPM, } \\
\text { Plinian Core, } \\
\text { EML }\end{array}$ & PopulationBiology & $\begin{array}{l}\text { Information about the number } \\
\text { of individuals per area or time } \\
\text { unit and abundance } \\
\text { information. }\end{array}$ \\
\hline & Conservation & EOL SPM & ConservationStatus & $\begin{array}{l}\text { A description of the likelihood } \\
\text { of the species becoming } \\
\text { extinct in the present day or in } \\
\text { the near future. }\end{array}$ \\
\hline & Legislation & $\begin{array}{l}\text { EOL SPM, } \\
\text { Plinian Core }\end{array}$ & Legislation & $\begin{array}{l}\text { Legal regulations or statutes } \\
\text { relating to the taxon - } \\
\text { International, National or } \\
\text { Regional. }\end{array}$ \\
\hline \multirow[t]{3}{*}{ UsesManagement } & Uses & Plinian Core & Uses & $\begin{array}{l}\text { Known or potential benefits of } \\
\text { the species for humans, at a } \\
\text { direct economic level, as } \\
\text { instruments of education, } \\
\text { prospecting, eco-tourism, etc. }\end{array}$ \\
\hline & FolkKnowledge & Plinian Core & FolkKnowledge & $\begin{array}{l}\text { Resources of folk knowledge } \\
\text { related to the taxon. }\end{array}$ \\
\hline & Management & Plinian Core & Management & $\begin{array}{l}\text { Describes techniques and } \\
\text { goals used in management of } \\
\text { species - breeding and } \\
\text { cultivation, control etc. }\end{array}$ \\
\hline \multirow{3}{*}{ DatasetDetails } & DatasetPurpose & IBIN & DatasetPurpose & Purpose of the related dataset \\
\hline & DatasetDescription & IBIN & DatasetDescription & Description of a related dataset \\
\hline & DatasetLink & IBIN & DatasetLink & Link to the related dataset \\
\hline \multirow[t]{4}{*}{ Patent Details } & PatentName & IBIN & PatentName & Name of the patent \\
\hline & PatentNumber & IBIN & PatentNumber & Number of the patent \\
\hline & PatentOwner & IBIN & PatentOwner & $\begin{array}{l}\text { Name of the person in whose } \\
\text { name the patent is issued. }\end{array}$ \\
\hline & ProductProcess & IBIN & ProductProcess & Details of the product process. \\
\hline
\end{tabular}




\begin{tabular}{|c|c|c|c|c|}
\hline & PatentDate & IBIN & PatentDate & $\begin{array}{l}\text { Date on which the patent is } \\
\text { issued. }\end{array}$ \\
\hline & PatentLink & IBIN & PatentLink & $\begin{array}{l}\text { Link, if any, to the patent } \\
\text { details. }\end{array}$ \\
\hline \multirow[t]{7}{*}{ Specimen Details } & TypeSpecimen & Plinian Core & TypeSpecimen & $\begin{array}{l}\text { Type description. It could be: } \\
\text { Holotype, Isotype, } \\
\text { Isolectotype, Kleptotype, } \\
\text { Paratype, Sintype. }\end{array}$ \\
\hline & TypeCollector & Plinian Core & TypeCollector & $\begin{array}{l}\text { Information about the person } \\
\text { who collected the type } \\
\text { specimen. }\end{array}$ \\
\hline & TypeDate & Plinian Core & TypeDate & $\begin{array}{l}\text { Date on which the type } \\
\text { specimen was collected. }\end{array}$ \\
\hline & TypeLocation & Plinian Core & TypeLocation & $\begin{array}{l}\text { Locality where the type } \\
\text { specimen was collected. }\end{array}$ \\
\hline & TypeDepository & Plinian Core & TypeDepository & $\begin{array}{l}\text { Name and Adress of } \\
\text { Institution where the type } \\
\text { specimen is hosted. }\end{array}$ \\
\hline & TypeRecord & Plinian Core & TypeRecord & $\begin{array}{l}\text { Record number of the type } \\
\text { specimen in depository. }\end{array}$ \\
\hline & TypeSource & Plinian Core & TypeSource & $\begin{array}{l}\text { Online link (if available) to } \\
\text { record in specimen depository. }\end{array}$ \\
\hline \multirow[t]{3}{*}{$\begin{array}{l}\text { Information } \\
\text { Listing }\end{array}$} & $\begin{array}{l}\text { Text } \\
\text { References/Publications }\end{array}$ & IBIN & $\begin{array}{l}\text { Text } \\
\text { References/Publications }\end{array}$ & $\begin{array}{l}\text { Compilation of all text } \\
\text { resources and publications } \\
\text { associated with/referred to/ } \\
\text { cited in entire page. }\end{array}$ \\
\hline & Documents & IBIN & Documents & $\begin{array}{l}\text { Links to all documents on IBP } \\
\text { referred to/associated with/ } \\
\text { used in this entire page. }\end{array}$ \\
\hline & External Links & IBIN & External Links & $\begin{array}{l}\text { Compilation of all URL's in } \\
\text { entire page that create outlinks } \\
\text { from IBIN species pages into } \\
\text { individual BRIC data } \\
\text { providers' web sites. }\end{array}$ \\
\hline \multirow[t]{5}{*}{$\begin{array}{l}\text { Observational } \\
\text { Information }\end{array}$} & Method & $\mathrm{ABCD}$ & TypeMethod & $\begin{array}{l}\text { Method (including technical } \\
\text { means) used to make the } \\
\text { collection or observation }\end{array}$ \\
\hline & AssociatedTaxa & $\mathrm{ABCD}$ & AssociatedTaxa & $\begin{array}{l}\text { Gives information about the } \\
\text { other taxa observed at the } \\
\text { gathering site }\end{array}$ \\
\hline & Sex & $\mathrm{ABCD}$ & SpecimenSex & $\begin{array}{l}\text { sex of a specimen or } \\
\text { collected/observed } \\
\text { individual(s) }\end{array}$ \\
\hline & Observed Weight & Darwin Core & SpecimenWeight & $\begin{array}{l}\text { The total biomass found in a } \\
\text { collection/record event. } \\
\text { Expressed as kg }\end{array}$ \\
\hline & SamplingEffort & Darwin Core & SamplingEffort & $\begin{array}{l}\text { The amount of effort expended } \\
\text { during an Event }\end{array}$ \\
\hline
\end{tabular}




\begin{tabular}{|c|c|c|c|c|}
\hline & Temperature & Darwin Core & Temperature & $\begin{array}{l}\text { The temperature recorded with } \\
\text { the collection/record event }\end{array}$ \\
\hline WMSURL & WMSURL & $\mathrm{ABCD}$ & WMSURL & $\begin{array}{l}\text { Indicates URI (e.g. web } \\
\text { address) for the location of a } \\
\text { boundary polygon or centroid } \\
\text { spatial reference relating to a } \\
\text { gathering site, according to the } \\
\text { Web Map Services (WMS) } \\
\text { specification of the Open GIS } \\
\text { Consortium. }\end{array}$ \\
\hline
\end{tabular}

\section{Results and Discussions}

This paper presented an approach to develop a toolkit through which the data coming from heterogeneous sources will be dynamically included into IBIN schema, prepared from data schema of globally understood standards. For this to happen, the compatibility of different standards used in IBIN standards and current existing standards is must which will be achieved by providing interoperability between systems on different platforms implemented by different technologies. Web Services provide a standard means of communication among different software applications, running on a variety of platforms and/or frameworks. The data will be published and indexed through the IBIN toolkit, and then the data will become available through IBIN infrastructure and can be used by the end users.

There are many challenges in developing and implementing this toolkit because web services and metadata standards are all new emerged technology and are undergoing changes and developments. The security of Services, the encryption of messages, and the common taxonomies to describe Services are all in need of consideration.

\section{REFERENCES}

ABCD (2016). ABCD - Access to Biological Collection Data. Retrieved October 22, 2018, from

http://www.dcc.ac.uk/resources/metadata-standards/abcdaccess-biological-collection-data

Bargmeyer, B. E., \& Gillman, D. W. (2000). Metadata standards and Metadata registries: an overview. Vasa.

Barkman, P., Brown, D., Brusilovsky, P., Burke, J. R., Fore, M., Hyde, J., Peoples, B. (2002). Draft Standard for Learning Object Metadata. Learning Technology Standards Committee of the IEEE.

https://doi.org/10.1109/IEEESTD.2002.94128

Berners-Lee, T., \& M., F. (1999). Weaving the web, the Original Design and Ultimate Destiny of the World Wide Web by its Inventor. HarperBusiness San Francisco. https://doi.org/10.1109/TPC.2000.843652
Bodoff, D., Hung, P. C. K., \& Ben-Menachem, M. (2005). Web metadata standards: Observations and prescriptions. IEEE Software. https://doi.org/10.1109/MS.2005.25

Canhos, V. P., Souza, S. De, Giovanni, R. De, \& Canhos, D. A. L. (2004). Global Biodiversity Informatics: setting the scene for a "new world" of ecological forecasting. Biodiversity Informatics. https://doi.org/10.17161/bi.v1i0.3

Carini, P., \& Shepherd, K. (2004). The MARC standard and encoded archival description. Library Hi Tech. https://doi.org/10.1108/07378830410524468

Chalmers, R. J. G. (2006). Health care terminology for the electronic era. Mayo Clinic Proceedings. https://doi.org/10.4065/81.6.729

Chan, L. M., \& Zeng, M. L. (2006). Metadata interoperability and standardization - A study of methodology part I: Achieving interoperability at the schema level. D-Lib Magazine. https://doi.org/10.1111/j.1468-0084.2006.00151.x

Costello, M. J., \& Wieczorek, J. (2013). Best practice for biodiversity data management and publication. Biological Conservation. https://doi.org/10.1016/j.biocon.2013.10.018

DCMI. (2007). Dublin Core Metadata Element Set, Version 1.1. Elements. https://doi.org/10.1108/02640470910966880

Dudeck, J. (1998). Aspects of implementing and harmonizing healthcare communication standards. In International Journal of Medical Informatics. https://doi.org/10.1016/S1386-5056 (97)00122-6

Duh, K. D. W., Duh, K. D. W., Dqg, Q., \& Dqg, Q. (2001). Metadata Standards: What, Who \& Why. Computer. https://doi.org/10.3217/jucs-007-07-0591

Duval, E. (2001). Metadata Standards: What, Who \& Why. Computer. https://doi.org/10.3217/jucs-007-07-0591

Federal Geographic Data Committee. (1998). Content standard for digital geospatial metadata, Version 2.0. FgdcStd-001-1998. 
Fegraus, E. H., Andelman, S., Jones, M. B., \& Schildhauer, M. (2005). Maximizing the Value of Ecological Data with Structured Metadata: An Introduction to Ecological Metadata Language (EML) and Principles for Metadata Creation. Bulletin of the Ecological Society of America. https://doi.org/10.1890/0012-9623 (2005)86[158: MTVOED] 2.0.CO;2

Forte, E., Haenni, F., Warkentyne, K., Duval, E., Cardinaels, K., Vervaet, E., \& Simillion, F. (1999). Semantic and pedagogic interoperability mechanisms in the ARIADNE educational repository. ACM SIGMOD Record, 28(1), 20-25

Fox, E. A., Akscyn, R. M., Furuta, R. K., \& Leggett, J. J. (1995). Digital libraries. Communications of the ACM, 38(4), 22-28.

Guenther, R., \& McCallum, S. (2003). New Metadata Standards for Digital Resources: MODS and METS. Bulletin of the American Society for Information Science and Technology. https://doi.org/10.1002/bult.268

Güntsch, A., Berendsohn, W., \& Mergen, P. (2007). The BioCASE Project - a Biological Collections Access Service for Europe. Ferrantia.

Harper, C. (2010). Dublin Core Metadata Initiative: Beyond the Element Set. Information Standards Quarterly. https://doi.org/10.3789/isqv22n1.201004

Haslhofer, B., \& Klas, W. (2010). A survey of techniques for achieving metadata interoperability. ACM Computing Surveys. https://doi.org/10.1145/1667062.1667064

Kohn, L. T., Corrigan, J. M., \& Donaldson, M. S. (2000). To err is human: building a safer health system. Annales francaises d'anesthesie et de reanimation. https://doi.org/10.1017/S095026880100509X

Kosch, H., Böszörményi, L., Döller, M., Libsie, M., Schojer, P., \& Kofler, A. (2005). The life cycle of multimedia metadata. IEEE Multimedia. https://doi.org/10.1109/MMUL.2005.13

LaPlant, W. P., Lestina, G. J., Gillman, D. W., \& Appel, M. V. (1996, March). Proposal for A Statistical Metadata Standard. In 1996 US Bureau of the Census Annual Research Conference.

McClelland, M. (2003). Metadata Standards for Educational Resources. Computer. https://doi.org/10.1109/MC.2003.1244540

Michener, W. K., Brunt, J. W., Helly, J. J., Kirchner, T. B., \& Stafford, S. G. (1997). Nongeospatial metadata for the ecological sciences. Ecological Applications. https://doi.org/10.1890/1051-0761 (1997)007[0330: NMFTES] 2.0.CO;2

National Information Standards Organization. (2005) ANSI/NISO Z39.19-2005: Guidelines for the Construction, Format, and Management of Monolingual Controlled Vocabularies. Management.

Paepcke, A., Chang, C.-C. K., Winograd, T., \& GarcíaMolina, H. (1998). Interoperability for digital libraries worldwide. Communications of the ACM. https://doi.org/10.1145/273035.273044

Richesson, R. L., \& Krischer, J. (2007). Data Standards in CLinical Research: Gaps, Overlaps, Challenges and Future Directions. Journal of the American Medical Informatics Association.

https://doi.org/10.1197/jamia.M2470.Introduction

Rust, G., \& Bide, M. (2000). The indecs metadata framework; Principles, model and data dictionary. Intellectual Property.

Schell, D., McKee, L., \& Buehler, K. (2000). Geodata Interoperability-A key NII Requirement. White Paper submitted to the NII. Resource Document.

$\mathrm{http} / / /$ portal.opengeospatial.org/files/?artifact_id $=6200 \& \mathrm{ve}$ rsion $=1 \&$ format $=$ pdf

Smith, J. R., \& Schirling, P. (2006). Metadata standards roundup. IEEE Multimedia.

https://doi.org/10.1109/MMUL.2006.34

Steinacker, A., Ghavam, A., \& Steinmetz, R. (2001).

Metadata standards for web-based resources. IEEE

Multimedia. https://doi.org/10.1109/93.923956

TDWG (2016). Tdwg/wiki-archive. Retrieved October 22, 2018, from https://github.com/tdwg/wikiarchive/blob/master/twiki/data/SPM/SpeciesProfileModel.t $\mathrm{xt}$

Tennant, R. (2001). Different Paths to Interoperability. Library Journal, 126(3), 118-119.

van Ossenbruggen, J., Nack, F., \& Hardman, L. (2004). That obscure object of desire: Multimedia metadata on the web, part 1. IEEE Multimedia.

https://doi.org/10.1109/MMUL.2004.36

Vetterli, T., Vaduva, A., \& Staudt, M. (2000). Metadata standards for data warehousing: open information model vs. common warehouse metadata. ACM Sigmod Record. https://doi.org/10.1145/362084.362138

Wieczorek, J., Bloom, D., Guralnick, R., Blum, S., Döring, M., Giovanni, R., Vieglais, D. (2012). Darwin core: An 
The International Archives of the Photogrammetry, Remote Sensing and Spatial Information Sciences, Volume XLII-5, 2018 ISPRS TC V Mid-term Symposium “Geospatial Technology - Pixel to People”, 20-23 November 2018, Dehradun, India

evolving community-developed biodiversity data standard.

PLoS ONE. https://doi.org/10.1371/journal.pone.0029715

Working group for the development of the Plinian Core

standard. (2017). Retrieved October 22, 2018, from

https://www.gbif.es/en/proyecto/plinian-core/ 